\title{
Quando a escola opera na conscientização dos jovens adolescentes no combate às DSTs
}

\section{When school operates in the awareness of young teenagers in the fight against STDs}

\author{
Renan da Silva ${ }^{1}$
}

\begin{abstract}
RESUMO
O objetivo deste estudo foi contribuir para o ensino das Doenças Sexualmente Transmissíveis (DSTs) nas escolas de Ensino Médio. O estudo foi feito a partir da investigação do nível de conhecimento sobre DST de 61 alunos de duas escolas de Rio Claro, SP: uma estadual e uma particular, através de um questionário (Pré-teste) e da entrevista com dois professores de Biologia, sendo um de cada escola. Os resultados indicaram que, de uma forma geral, os alunos da escola particular tinham mais conhecimento a respeito do tema. Os alunos da escola pública mostraram mais dificuldade com relação ao conhecimento (conhecimento ou informação?) sobre os sintomas das DSTs. Nas duas escolas o conhecimento sobre o assunto se mostrou genérico e superficial. De acordo os professores de Biologia, ambos ensinam sobre o conteúdo e o material didático contém os temas de sexualidade e DST. A partir desses resultados foi elaborada uma intervenção com os alunos, usando como metodologia a dinâmica de grupo e a aula expositiva dialogada. Após a intervenção verificou-se um aumento da porcentagem de respostas corretas dos alunos de ambas as escolas (Pós-teste), o que demonstra que ela foi eficaz. Concluímos que este trabalho alcançou o objetivo de esclarecer o tema aos alunos, porém, falta às escolas um melhor diálogo com eles para o planejamento desse conteúdo, já que, embora seja previsto o seu ensino, não está havendo uma aprendizagem esperada.
\end{abstract}

Palavras-chave: adolescência; DST; educação e saúde; educação sexual; Ensino Médio.

DOI: $10.1590 / 0104-4060.41170$

1 Universidade Estadual Paulista "Júlio de Mesquita Filho". Campus de Rio Claro. Rio Claro, São Paulo, Brasil. Av. 24 A, n 1515. CEP:13506-900.E-mail: lepp@rc.unesp.br 


\begin{abstract}
The aim of this study was to contribute to the teaching of Sexually Transmitted Diseases (STDs) in High Schools. The study was done from the research knowledge about STDs of 61 students from two schools of Rio Claro, SP: a state and a private school, through a questionnaire (Pre-test) and an interview with two Biology professors, each one from each school. The results indicated that, in general, the students in the private school had more knowledge about the subject. The public school students showed more problems with knowledge (knowledge or information?) about the symptoms of STDs. In those two schools the knowledge on the subject proved to be generic and superficial. According to the Biology teachers, both of them teach about the content and the teaching material contains themes of sexuality and STDs. From these results, an intervention was developed with students, using methods such as group dynamics and lecture dialogued lessons. After the intervention, there was an increase in the percentage of correct answers for the students of both schools (Post-test) which shows that it was effective. We conclude that this work has achieved its goal to enlighten students on the topic, but schools fail to have a better dialogue with their students for the planning of such content, since although its teaching is expected, learning is not happening as expected.
\end{abstract}

Keywords: adolescents; STDs; education and health; sexual education; High School.

\title{
Introdução
}

O que motivou este trabalho foi o interesse em saber mais a respeito da incidência de DST na adolescência, compreender por quais razões os jovens são tão atingidos por essas doenças e entender se o conhecimento que eles têm a respeito se relaciona com o tipo de escolas frequentadas, se particular ou pública. Assim, na disciplina de Prática como Componente Curricular (PCC) no curso de Licenciatura em Ciência Biológicas da Unesp - Campus Rio Claro, houve a possibilidade de dar início a este estudo e, assim, desenvolver um projeto concreto.

A adolescência é um período de transição entre a infância e a idade adulta, em que os jovens passam por um intenso desenvolvimento e grandes transformações. Todas as mudanças que ocorrem podem interferir no processo natural de maturidade e formação, trazendo curiosidades que levam os jovens a experimentar alguns comportamentos que fazem deles mais vulneráveis a riscos 
para a saúde, incluindo o aspecto sexual. Por vulnerável estamos entendendo os fatores que estão presentes em seu ambiente e que na interação com os aspectos inerentes à fase da adolescência podem aumentar um resultado negativo na presença de risco. (GARCIA, 2001). Em razão disso, se faz necessário, nessa etapa de suas vidas, que esses adolescentes recebam informações corretas a respeito de sexualidade, dos riscos, precauções e cuidados, principalmente, porque iniciam sua vida sexual.

Informação não garante o conhecimento, mas é a sua base. O conhecimento se constrói a partir da informação; ele resulta da interação do sujeito com o objeto e tem a ver com a interpretação pessoal, que pela experiência, confere significado ao objeto. É a forma como se apreende a informação e se aprende um conteúdo. Esta apreensão é totalmente individual e pessoal, mas tem um vínculo com o saber universal e com a comunidade científica. (WERNECK, 2006). Estamos aqui falando de um conhecimento empírico, não necessariamente científico, já que este é que se pretende construir com o aluno, inclusive a partir do que ele sabe.

Essas informações podem partir de diversas fontes, como família, amigos e escola. Porém, alguns estudos indicam que a família não é muito citada como fonte de informação sobre sexualidade e DST. (COSTA et al., 2010). Os estudos de Brêtas (2009) afirmam que os pais têm dificuldades de abordar o tema sexualidade com seus filhos adolescentes, por não terem tido espaço para isso quando mais jovens. Assim, os pais atribuem esse papel à escola e esta, por sua vez, tem dificuldades em cumpri-lo, pois os professores, muitas vezes, se sentem despreparados.

Por outro lado, temos a escola como uma instância importante para a educação em saúde, portanto, devendo contemplar temas como DST/AIDS, Sexualidade, Drogas. (COSTA et al., 2010). Verificando os Parâmetros Curriculares Nacionais (PCN) elaborados pelo Ministério da Educação (MEC), pode-se observar que este assunto está incluído no programa, dentro dos Temas Transversais. (BRASIL, 1998).

Ocorre que, em várias regiões do Brasil, essa função não é adequadamente exercida, seja por falta de recursos humanos, financeiros ou de materiais que trabalhem com este tema. (MAIA; ARANHA, 2005; COSTA et al., 2010). Para que haja uma orientação sexual na escola é necessário que existam professores que se sintam preparados para exercer tal papel. Cabe aqui lembrar que esta dificuldade não está desvinculada das questões sociais e econômicas que determinam o sistema educacional brasileiro. Apesar de a temática sexualidade estar incorporada no PCN como tema transversal, devendo assim ser tratada por professores de qualquer disciplina, ainda esse papel é geralmente atribuído apenas aos professores de Ciências e Biologia. No entanto, como mostrado no 
estudo de Jardin e Brêtas (2006), os professores ainda não possuem subsídios para trabalhar questões sociais, como valores, preconceitos e tabus que envolvem essa temática e em razão disso acabam se restringindo apenas aos aspectos biológicos da sexualidade. Os professores ainda se sentem inseguros com seus próprios conhecimentos para falar com seus alunos se utilizando, assim, quase exclusivamente, do conhecimento dos livros de Ciências e Biologia. (JARDIN; BRÊTAS, 2006; SOUZA et al., 2008). Portanto, acabam sendo professores dessas disciplinas os principais e, às vezes, os únicos responsáveis por trabalhar o assunto com os alunos e, ainda assim, somente com o conteúdo trazido nos livros didáticos, como também mostra o estudo de Jardin e Brêtas (2006, p. 161), que se resume à fisiologia da reprodução, anatomia e temas tradicionais da adolescência como a prevenção da gravidez e das DSTs/AIDS.

Sabe-se que a população jovem é considerada a mais vulnerável às DSTs, principalmente HIV. (BRASIL, 2011a). Segundo dados da Organização Mundial da Saúde, a maioria dos jovens dá inicio à sua vida sexual cada vez mais cedo, geralmente entre 12 e 17 anos. (CASTRO et al., 2004). Estima-se que no Brasil, a cada ano, quatro milhões de jovens tornam-se sexualmente ativos e que ocorram cerca de 12 milhões de DSTs ao ano, das quais, um terço em indivíduos com menos de 25 anos. (CASTRO et al., 2004).

Assim, o desconhecimento do modo de contágio das DSTs e a falta de informação sobre os métodos preventivos facilitam as transmissões por vias sexuais, ficando clara a necessidade de se adotar práticas educativas mais eficientes no ambiente escolar.

Nesse contexto, elaborou-se este estudo que tem como objetivo, primeiramente, comparar o conhecimento sobre DST em uma escola estadual e em uma particular de Ensino Médio, e após esse levantamento, investigar se o professor de Biologia aborda este tema e, finalmente, contribuir com uma intervenção pedagógica sobre este conteúdo.

\section{Metodologia}

Trata-se de uma pesquisa do tipo pesquisa-ação, ou seja, ao mesmo tempo em que se busca explorar um tipo de conhecimento, também intervém nos resultados. Além disso, ela pretende resolver problemas de ordem prática e tem um caráter interrogativo-crítico. (THIOLLENT, 2009). 


\section{Aplicação dos questionários}

Foram aplicados questionários (Pré-Teste) em duas turmas de primeiro ano do Ensino Médio, de uma escola pública com 27 alunos e de uma escola particular com 34 alunos, sem restrição sexual, de etnia, classe, grupo social, ou estado de saúde; as duas salas foram selecionadas por sorteio. Os questionários apresentavam 20 questões, sendo algumas dissertativas e outras de múltipla escolha, nas quais podiam ser assinaladas mais de uma alternativa, caracterizando-o como um questionário do tipo misto, com perguntas abertas e fechadas. O questionário era composto de duas seções, sendo uma com perguntas de características sociodemográficas e a outra com perguntas sobre DST. O questionário foi respondido individualmente. Antes de ser aplicado aos alunos foi esclarecido que eles não eram obrigados a respondê-lo inteiro ou qualquer pergunta e que podiam parar de responder quando quisessem. Em média os questionários foram respondidos em 15 minutos. Os resultados foram passados para uma planilha do Excel e foram calculadas as porcentagens das respostas para comparação entre as escolas.

\section{Aplicação da entrevista com os professores}

Durante um intervalo das aulas, foi feita uma entrevista com um professor de Biologia de cada escola, dentro da sala de aula. As respostas dos professores foram anotadas e depois passadas para uma planilha. A entrevista foi composta de 2 seções, sendo uma com perguntas de características sociodemográficas e a outra com perguntas que visavam levantar o conhecimento sobre como a escola e o professor trabalham o tema das DSTs com os alunos.

\section{Intervenção}

A intervenção teve início com a aplicação de uma dinâmica de grupo com os alunos. Foram formados 3 grupos e foi entregue a cada grupo cartões com os nomes das principais DSTs e outros com seus respectivos sintomas. Os alunos tinham que ligar a doença ao seu sintoma. Após 15 minutos, as respostas foram analisadas e aproveitadas para explicar as doenças em que os alunos estavam tendo dificuldades de saber. Após essa dinâmica demos início a uma aula expositiva sobre o assunto, utilizando slides.

Nessa apresentação foi explicado, primeiramente, o motivo do projeto, esclarecendo a grande ocorrência de DST entre os jovens. Em seguida foram explicadas as principais doenças sexualmente transmissíveis, seus sintomas, prevenções, tratamentos, forma de transmissão, possibilidade de cura, ilustrando com fotos cada doença. Ao final, foram trabalhados alguns mitos existentes 
sobre o assunto de forma dialogada. Por último, foi discutido sobre a prevenção desse tipo de doença e demonstrado a colocação correta da camisinha masculina, através de ilustrações. Ao final da intervenção, foram aplicados novamente os questionários (Pós-Teste) da mesma maneira que foram aplicados da primeira vez, para que fosse possível verificar os resultados da intervenção.

\section{Resultados e discussão}

Segundo a entrevista feita com os professores, obtivemos os seguintes dados: tanto o professor da escola pública, como da particular, prevê este conteúdo no programa e o conteúdo é abordado no livro didático. A diferença é que o professor da escola pública relata que o conteúdo está previsto no projeto pedagógico da escola.

De acordo com Vygotsky (1995), o desenvolvimento está intimamente relacionado ao contexto sociocultural em que a pessoa se insere e se processa de forma dinâmica através de rupturas e desequilíbrios provocadores de contínuas reorganizações por parte do indivíduo. E em razão disso, como já mostra o trabalho de Silva e Carvalho (2005), existe uma necessidade de preparar essas aulas de uma forma específica para cada turma, levando em consideração as particularidades de seus alunos. Cada classe apresenta interesses diferentes que variam com a vivência de cada um, com a idade e com a educação vinda da família, e o material didático facilita essa preparação, selecionando os mais adequados para o conteúdo de interesse.

$\mathrm{Na}$ verdade, o material didático deve conter esse conteúdo, ele faz parte dos Parâmetros Curriculares Nacionais (BRASIL, 1998), nos Temas Transversais - como já dito anteriormente - que garantem aos educadores instrumentos para tratar tal tema com seus alunos. Embora se espere que os professores de Biologia trabalhem sobre este conteúdo, deve-se lembrar que a responsabilidade da educação sexual deve ser da escola como um todo. (SAITO; LEAL, 2000).

Quando os professores foram perguntados a respeito do interesse dos alunos sobre o tema, eles responderam que estavam interessados e costumavam questioná-los a respeito (este aspecto foi constatado no momento da intervenção, pela atenção observada nos alunos e quantidade de questionamentos que fizeram).

Os professores disseram, ainda, que trabalham com todos os aspectos importantes das DSTs, como: tipos de doenças, as maneiras de prevenção, de tratamento e formas de contágio. De acordo com o estudo de Ribeiro e Souza (2003), essa temática é vista nos materiais pedagógicos como: guias de educação sexual, manuais, livros didáticos, e nos temas transversais Orientação 
Sexual (PCN). Isto se relaciona, principalmente, aos métodos anticoncepcionais, conhecimento anatômico e fisiológico dos sistemas reprodutores, à prevenção das doenças sexualmente transmissíveis. O assunto é abordado como problema de saúde sexual e reprodutiva, através de discursos médicos e biológicos para prescrever um cuidado e, assim, controlar o corpo e a sexualidade. Alguns livros didáticos citados no estudo de Bellini e Frasson (2006) abordam o tema das DSTs em seu conteúdo, como em Lopes (2003), Favaretto e Mercadante (2003), Soares (1999), Fonseca (1999), entre outros.

O professor da escola pública relatou que utiliza leitura de textos, figuras e data show para transmitir o conteúdo. O professor da escola particular explicou que para trabalhar o assunto com os alunos utiliza a metodologia de seminários, em que um dos temas são as DSTs, e ao final faz perguntas e complementa a explicação a partir das dúvidas e curiosidades que os alunos apresentam. Ao montar os seminários, os alunos precisam pesquisar e estudar a respeito do tema abordado e esta metodologia, muitas vezes, desperta a curiosidade deles em algumas questões, que posteriormente serão sanadas em aula pelo professor.

Com relação aos alunos, foi verificado, através da comparação das respostas do questionário representados no Gráfico 1, que o conhecimento prévio dos alunos foi satisfatório nas duas escolas, porém, é notável um maior conhecimento dos alunos da escola particular. O conhecimento básico a respeito do que são as DSTs foi satisfatório; praticamente todos os alunos associaram DST com doenças transmitidas sexualmente, porém, cerca de $80 \%$ desses alunos não sabiam que havia outras formas de transmissão. Esses resultados se assemelham aos de outros trabalhos, como o de Brêtas et al. (2009).

GRÁFICO 1 - CONHECIMENTO GERAL DOS ALUNOS SOBRE O QUE SÃO AS DSTs

\section{Conhecimento básico sobre DST}

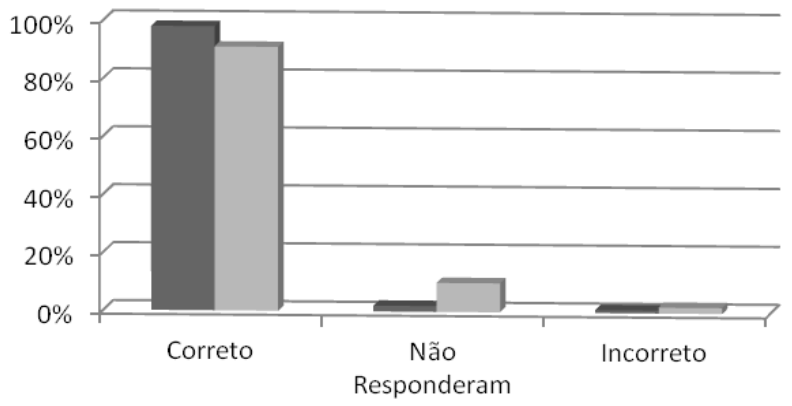

Escola Particular

n Escola Pública

FONTE: O autor (2015). 
Sobre saber da existência de alguma DST, se observa que o conhecimento dos alunos da escola pública é mais precário do que os da escola particular. $\mathrm{Na}$ escola pública, $78 \%$ dos alunos disseram que conheciam alguma DST, enquanto que, na particular, $100 \%$. Na escola particular também foi perceptível a maior diversidade de conhecimento de doenças do que na escola pública, como pode ser visto no gráfico a seguir.

\section{GRÁFICO 2 - FREQUÊNCIA EM QUE CADA DOENÇA FOI CITADA PELOS ALUNOS DE CADA ESCOLA}

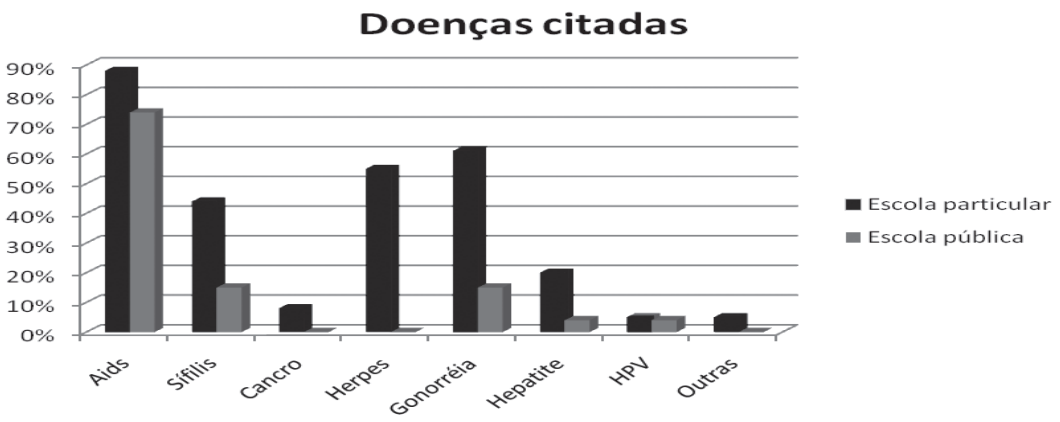

FONTE: O autor (2015).

Em relação à transmissão das DSTs, na escola pública 54\% dos alunos disseram que elas ocorrem apenas por contato sexual e na escola particular apenas $26 \%$ dos alunos assinalou essa alternativa. A porcentagem dos alunos que respondeu que pode ocorrer por contato sexual e sanguíneo foi muito próxima entre as duas escolas, em torno de $95 \%$. Muitos deram as duas respostas, mostrando uma contradição. Isso pode ter ocorrido devido ao fato da primeira alternativa do questionário ser apenas a relação sexual, talvez os levando a uma dedução.

Outra disparidade entre as duas escolas foi percebida quando os alunos responderam sobre outras formas de transmissão. Nenhum estudante da escola pública fez menção sobre isso, enquanto $14 \%$ dos alunos da escola particular especificaram o contato direto com feridas de algumas DSTs, com objetos hospitalares contaminados, com a mucosa e a transmissão de mãe para o filho durante o parto.

Com relação aos sintomas, observou-se uma grande diferença entre o conhecimento das duas escolas. O gráfico 3 demonstra que a escola pública apresentou resultados muito insatisfatórios, visto que cerca de $85 \%$ dos alunos não responderam ou não conheciam qualquer sintoma das DSTs. O conhecimento da escola particular, apesar de mostrar melhores resultados, ainda não é 
considerado suficiente. É importante destacar que a identificação de um sintoma é de extrema importância para um diagnóstico mais rápido e mais eficiente de uma DST, pois quando não diagnosticada pode trazer danos irreparáveis para a vida dos pacientes. Esse resultado também foi observado no trabalho de Brêtas et al. (2009).

GRÁFICO 3 - PORCENTAGEM DE ALUNOS QUE CONHECEM ALGUM SINTOMA DE DST

\section{Conhecem algum sintoma}

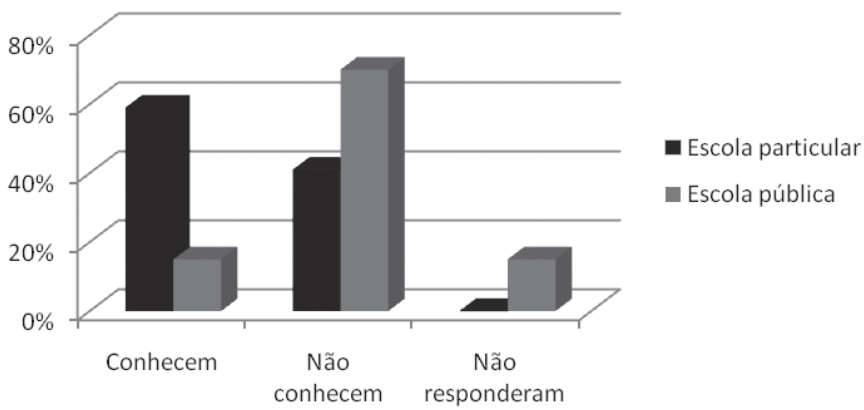

FONTE: O autor (2015).

TABELA 1 - PORCENTAGEM DE RESPOSTAS CORRETAS DADAS PELOS ALUNOS DE CADA ESCOLA

\begin{tabular}{ccc}
\hline Assuntos & Escola Particular & Escola Pública \\
\hline Métodos de Prevenção & $91 \%$ & $70 \%$ \\
Existência de Cura & $71 \%$ & $33 \%$ \\
Existência de Vacinas & $41 \%$ & $33 \%$ \\
Tratamentos & $72 \%$ & $70 \%$ \\
\hline
\end{tabular}

FONTE: O autor (2015).

Sobre os métodos de prevenção, novamente os alunos da escola particular demonstraram um maior conhecimento, como pode ser visto na Tabela 1.

Os dados demonstram que a frequência de alunos da escola pública que associam DST diretamente à AIDS é maior na escola pública; com relação à cura das DSTs, a maioria (77\%) não acredita que há cura. Na verdade, todas as DSTs, exceto as virais (AIDS, HPV, Herpes), têm cura, se tratadas adequadamente. (BRÊTAS et al., 2009). Sobre o conhecimento de vacinas para o 
tratamento, apenas 7 alunos (20\%) da escola privada citaram a vacina para o $\mathrm{HPV}$, enquanto que na sala da escola pública nenhum estudante citou qualquer vacina. Atualmente as únicas vacinas existentes para DSTs são para Hepatite B e HPV. (PINHEIRO; ZEITOUNE, 2008; BONETTO et al., 1998; SIMÕES, 2010). Possivelmente por existir vacinas para poucas DSTs o conhecimento deles sobre estas não seja suficiente. O Ministério da Saúde incorporou recentemente a vacina contra HPV ao Sistema Único de Saúde (SUS) já para o início do ano letivo de 2014 para meninas de 10 a 13 anos. A vacina protegerá as meninas contra quatro variáveis do papilomavírus (HPV), que são responsáveis por 70\% dos casos de colo de útero. Esta é a primeira vez que a população terá acesso gratuito a uma vacina que protege contra câncer. (BRASIL, 2013).

Constata-se que 7 alunos citaram a existência de tal vacina, o que vem comprovar que esse dado foi trabalhado em sala de aula, como dito pelo professor, mas como foi em forma de seminário, provavelmente só foi assimilado pelo grupo de alunos que apresentou, ou seja, esse método pode ser eficaz para o aprendizado, mas, em geral, apenas os alunos que estudaram e pesquisaram aprendem. $\mathrm{O}$ restante da sala pode não dar a devida atenção na hora da explicação ou esquecer mais rapidamente aquilo que foi abordado na apresentação. De acordo com Veiga (1996, p. 112), o seminário, como técnica de ensino, é de grande valia para o ensinamento de temas novos ou para aprofundar um assunto mais polêmico, pois é uma excelente técnica para estimular a produção do conhecimento. Porém, Veiga também constata que o sucesso desse método dependerá em parte do professor e em parte do aluno. Balzan (1980, p. 121) apresenta alguns equívocos com relação a essa técnica, como a extrema divisão do trabalho, a descontinuidade e a ausência de interação. Novamente Veiga (1996, p. 109) aponta alguns relatos de alunos que dizem que: "algumas vezes, os alunos não preparam direito e o assunto fica mais superficial"; "que o aluno não transmite de uma forma boa e o aluno que não leu não tem condições de discutir"; "e ainda que, quem não faz o seminário não aprende nada". Isso mostra a necessidade de todos os alunos da sala estudarem e estarem inteirados do tema, para assim participar e se interessar pelo conteúdo que está sendo passado pelo colega. Cabe ao professor conduzir o seminário da melhor maneira.

Sobre os tratamentos das DSTs, as respostas das duas escolas foram parecidas: $72 \%$ na escola particular e $70 \%$ na pública responderam que existe tratamento, porém poucos alunos citaram o tipo de tratamento. A fonte de conhecimento dos alunos foi, em primeiro lugar, a escola. Os próprios professores relataram na entrevista que os alunos os procuram para tirar suas dúvidas. Este fato reforça a importância de se investir na educação sexual dos adolescentes.

$\mathrm{Na}$ escola pública, a segunda fonte de informação mais citada foi a família, com $44 \%$; já na escola particular, foram os livros e a internet, com $41 \%$, e na 
família aparece como resposta de $29 \%$ dos alunos. Tinsley, Lees e Sumartojo (2004) avaliaram a perspectiva da família na comunicação e observaram que a comunicação entre pais e filhos está positivamente relacionada às condutas preventivas dos adolescentes. Esses pesquisadores ainda constataram que famílias de baixa renda estabelecem conversas sobre sexualidade e HIV, o que faz com que esses adolescentes tenham mais habilidade para lidar com sua sexualidade. Esses resultados divergem do que foi demonstrado por Brêtas et al. (2009), em que a família foi uma das últimas fontes citadas pelos alunos, e também divergem do trabalho de Parker (2000), em que a conversa sobre sexualidade com os filhos ainda seria um tabu na cultura brasileira.

Já nos estudos de Castro et al. (2004), a proporção de conhecimento adquirido através de colegas e das mães, em específico, é muito próxima, o que sugere que amigos e pais (principalmente as mães) são fontes importantes dessas informações. Isto revela a importância das relações sociais na aquisição do conhecimento. Além disso, o diálogo na família sobre a sexualidade é, na verdade, imprescindível, já que o tema é complexo e envolve a intimidade. Esta é uma das dificuldades das escolas, que acabam não tratando esse tema abertamente, ou de forma mais informal. Normalmente, é feito o contrário, o tema é tratado em forma de palestras, o que pode inibir os alunos de fazerem perguntas relacionadas, já que esse ainda é um assunto pouco falado. A presença dos colegas também pode inibir os adolescentes de questionar os professores em público, o que os levam a sanar as curiosidades com os pais ou amigos ou como os próprios professores de Biologia relataram, de o fazerem de forma particular.

De qualquer forma, está bem clara a influência do contexto desses alunos e das suas condições sociais. Na classe mais favorecida, representada pela escola particular, observa-se o acesso a meios mais seletivos, de certa forma, como internet e livros; o que já não acontece com a classe menos favorecida, ou seja, os alunos que estudam nas escolas públicas, em que há falta de acesso a esses meios, provavelmente acabam favorecendo as relações com a família.

A respeito do que os alunos gostariam de saber sobre DST, houve uma grande diferença entre as escolas. Na escola pública notou-se que $52 \%$ não gostariam de saber nada ou não responderam. O maior índice de questões não respondidas ocorreu na escola pública.

Este resultado pode indicar o desconhecimento deles sobre o assunto ou o desinteresse. Ferreira et al. (2007) verificaram que as causas do desinteresse dos alunos, atualmente, variam desde a falta de aulas expositivas, atitude autoritária ou descaso de alguns professores, falta de estrutura escolar, falta de incentivo e exemplo dos pais, até o desenvolvimento de outras atividades como o trabalho. $\mathrm{O}$ fato dos alunos de escola pública apresentarem maior necessidade para ajudar nas despesas familiares pode interferir neste desinteresse. 
Por outro lado, os alunos de classes menos favorecidas pensam a escola diferente dos jovens das classes mais abastadas, o que reflete diretamente na aquisição e valorização do conhecimento e, sobretudo, na sua relação com o saber. Nem poderia ser diferente, uma vez que a relação com o saber é uma relação social, ou seja, é determinada pela sua condição de vida e, isso, reflete nas relações sociais que estruturam nossa sociedade, embora sejam singulares. (CHARLOT, 1996). Por exemplo, 30 anos atrás nem se cogitaria falar sobre este assunto tratado aqui, na escola.

$\mathrm{Na}$ escola particular o índice de questões não respondidas foi de $34 \%$. Embora a princípio tenhamos a tentação de pensar que esta diferença se deva a melhor estrutura das escolas particulares, a realidade é outra. Existe sim uma grande distância entre as escolas, principalmente com relação ao desempenho, porém, as escolas particulares têm demonstrado sinais de crise, principalmente verificado em 2005 através dos dados do Sistema de Avaliação da Educação Básica (Saeb), nas regiões mais desenvolvidas do Brasil e na Matemática. Também se verifica que ambas as escolas passam praticamente pelas mesmas dificuldades, porque pertencem ao mesmo sistema educacional. Atribui-se este resultado, principalmente, ao instrucionismo e reprodutivismo.

Este resultado também pode estar relacionado ao fato da escola, seja particular ou pública, não investir na aprendizagem do aluno e do professor, mas em aulas e provas. A escola particular, na verdade, está aquém do esperado, a despeito da fama que carrega. (DEMO, 2007).

Pode ser também que a pesquisa tenha justamente medido este conhecimento reprodutivista, daí esta diferença favorável da escola particular. Além disso, temos o investimento das escolas particulares no vestibular, o que reflete negativamente em conteúdos que têm como objetivo o bem-estar e a saúde do aluno e da sociedade acima de tudo.

De qualquer forma, o investimento na escola pública é fundamental, uma vez que a maioria dos alunos está na rede pública de ensino. Segundo dados do MEC, em 2010, a rede estadual recebia 85,9\% dos alunos e a rede particular 11,8\%. (ORGANIZAÇÃO DOS ESTADOS IBERO-AMERICANOS, 2010).

De acordo com o Instituto Nacional de Estudos e Pesquisas Educacionais Anísio Teixeira (Inep), no censo realizado em 2012, a rede estadual continua a ser a maior responsável pela oferta de Ensino Médio e tem $85 \%$ das matrículas, as redes federal e municipal possuem pouco mais de $2 \%$, enquanto que a rede privada tem $12,7 \%$ das matrículas.

Um estudo sobre o conhecimento de métodos anticoncepcionais entre alunos da escola pública e da escola particular no município de São Paulo revelou que ambos tinham pouco conhecimento a respeito, embora destaque que as diferenças socioeconômicas e culturais podem influenciar neste tipo de 
conhecimento. Também ficou demonstrado um conhecimento um pouco maior nos adolescentes das escolas privadas como, por exemplo, quanto ao número de métodos anticoncepcionais. Sendo assim, embora os alunos de um nível socioeconômico maior possuam informações de melhor qualidade, elas ainda não se mostram suficientes. (MARTINS et al., 2006). Já em pesquisa sobre o nível de conhecimento sobre a percepção de riscos sobre o HIV entre os anos de 1998 e 2005, o nível socioeconômico e o nível de escolaridade fizeram diferença. Mas a pesquisa chama a atenção para o fato de que entre jovens de 16 a 24 anos não houve aumento do conhecimento a respeito. (FERREIRA, 2008). Estes resultados, mais uma vez, reforçam o nosso trabalho que visa transmitir informações sobre o assunto e gerar conhecimento entre os jovens.

\section{A intervenção}

No momento da intervenção, os alunos das duas escolas se mostraram, no geral, bastante interessados pelo assunto, a maior parte interagiu e fez questionamentos. Durante as apresentações observou-se que as imagens traziam mais impacto para os alunos: quando apareciam algumas fotografias, os adolescentes ficavam bem agitados e surpresos e começavam a fazer comentários uns com os outros, causando um pouco de desordem, o que é normal nesta fase. Além disso, a interação faz parte da aprendizagem.

Após a intervenção houve um aumento de aproximadamente $6 \%$ do número de respostas completas e corretas (baseadas no Pós-teste) da questão "o que é uma DST" nas duas escolas. Na escola particular, todos os alunos responderam essa questão, já na escola pública houve um aumento de $5 \%$ no número de alunos que não respondeu. Talvez isso possa ser explicado pelo desinteresse que foi demonstrado por alguns alunos no momento da aplicação do questionário. Quanto ao conhecimento de alguma DST, houve um aumento de 17\% do número de alunos da escola pública que responderam que conheciam alguma doença. Mas nas duas escolas os alunos mostraram conhecer uma maior diversidade de doenças após a intervenção.

Em relação ao modo de transmissão, foi possível perceber um grande aproveitamento pelos alunos da escola pública, com $35 \%$ das respostas corretas, ou seja, pelo contato sexual e sanguíneo. Em relação à porcentagem de alunos que não respondeu esta questão anteriormente, houve um aumento de $44 \%$ do número de alunos que respondeu após a intervenção, o que é positivo, pois isso demonstra que houve aprendizagem e houve mais interesse, possivelmente. 
Quanto aos sintomas das DSTs, houve um aumento de cerca de $65 \%$ no número de alunos da escola pública que disseram conhecer algum sintoma, enquanto que na escola particular todos os alunos conheciam.

O conhecimento sobre os métodos de prevenção aumentou em cerca de $12 \%$ na escola pública e $6 \%$ na escola particular. Sobre a existência de vacinas, na escola pública, com um aumento de $28 \%$, a maioria dos alunos respondeu que algumas DSTs têm vacina. Na escola particular 100\% dos alunos responderam que existem vacinas para algumas DSTs.

$\mathrm{Na}$ escola pública, a maioria dos estudantes ainda acredita que as DSTs não possuem cura, ao contrário da particular. Em relação ao tratamento, houve um aumento nas duas escolas dos alunos que acreditam que há tratamento.

A seguir, apresenta-se uma síntese dos resultados, ficando clara a comparação entre os dados e a aprendizagem observada após a intervenção.

TABELA 2 - COMPARAÇÃO DO ANTES E DEPOIS DA INTERVENÇÃO

\begin{tabular}{lcccc}
\hline \multicolumn{1}{c}{ Questionamentos } & $\begin{array}{c}\text { Particular } \\
\text { antes da } \\
\text { intervenção }\end{array}$ & $\begin{array}{c}\text { Particular } \\
\text { após a } \\
\text { intervenção }\end{array}$ & $\begin{array}{c}\text { Pública } \\
\text { antes da } \\
\text { intervenção }\end{array}$ & $\begin{array}{c}\text { Pública } \\
\text { após a } \\
\text { intervenção }\end{array}$ \\
\hline Sabem o que são DSTs & $91 \%$ & $97 \%$ & $75 \%$ & $81 \%$ \\
Conhecem alguns sintomas & $59 \%$ & $100 \%$ & $15 \%$ & $65 \%$ \\
Sabem as prevenções & $91 \%$ & $97 \%$ & $70 \%$ & $82 \%$ \\
Sabem da existência de vacinas & $41 \%$ & $100 \%$ & $33 \%$ & $61 \%$ \\
Sabem que algumas possuem cura & $71 \%$ & $88 \%$ & $33 \%$ & $47 \%$ \\
Sabem da existência de tratamento & $72 \%$ & $88 \%$ & $70 \%$ & $81 \%$ \\
\hline
\end{tabular}

FONTE: O autor (2015).

Uma alternativa para a intervenção em escolas públicas e particulares seria as escolas reservarem um período de seu calendário escolar para atividades de esclarecimento sobre os perigos que o sexo praticado sem proteção pode trazer, mostrando aos alunos que as doenças sexualmente transmissíveis são as mais variadas possíveis, entretanto, em sua grande maioria, elas possuem tratamento e, principalmente, meios de serem evitadas. (MARQUES et al., 2006).

\section{Considerações finais}

Com relação à comparação do conhecimento entre a escola pública e a privada, consideramos que o conhecimento prévio dos alunos da escola particular se mostrou mais abrangente do que dos alunos da escola pública. Foi 
possível notar essa diferença nos conteúdos sobre exemplos de DST, modos de transmissão, sintomas, métodos de prevenção e existência de cura. Essa diferença ocorreu devido a vários fatores, dentre eles, o mais importante, que são as condições de vida de cada segmento, influenciando no acesso ao conhecimento e no interesse dos alunos. É importante salientar que mesmo sendo previsto o conteúdo em ambas as escolas - como foi dito pelos professores - é natural que o efeito, a metodologia, as relações, a visão de mundo determine as diferenças na aprendizagem. $\mathrm{O}$ mesmo pode ser considerado quanto ao sentido que este tipo de conhecimento faz a uma e a outra escola.

Foi possível perceber que o conhecimento a respeito das DSTs, independente de ser na escola pública ou particular, é superficial e incipiente, possivelmente por esse tema não ser trabalhado de uma forma mais aprofundada nas escolas. Isto é preocupante porque é certo que nessa fase da adolescência eles estão iniciando sua vida sexual e o conhecimento é uma das formas para a prevenção das DSTs.

Já com relação à intervenção, ficou demonstrado que ela atuou positivamente para a aquisição do conhecimento dos alunos, ampliando-se, trazendo mais contribuição para a escola pública. Atribuem-se, como uns dos fatores, a metodologia utilizada e o fato de sermos um elemento novo na escola. Acredita-se que quando esse tema é trabalhado de uma maneira diferente, ou seja, através de uma dinâmica de grupo ou uma conversa não tão formal quanto uma aula, os alunos dedicam mais de sua atenção, absorvendo mais o conteúdo e assim ampliam seus conhecimentos.

A partir desses dados pode-se assumir que a intervenção foi válida, sendo que houve um aumento satisfatório do número de respostas corretas em relação ao Pré-teste. Os dados da pesquisa mostram que, em geral, a maioria dos alunos passou a conhecer métodos para se evitar essas doenças, além de evidenciar um aumento no número de doenças conhecidas por eles. Isso mostra que a intervenção despertou curiosidade nos alunos sobre o assunto DST e foi capaz de sanar as dúvidas de grande parte dos envolvidos na intervenção.

Embora a contribuição tenha sido pontual, ela pode ser absorvida pela escola, podendo ser aproveitada pelos professores. Também é importante que a escola tenha essa noção, sobre as lacunas do conhecimento do aluno e da importância de se investir na educação sexual deles. Além disso, esta experiência foi muito importante como formação na Universidade, já que permitiu aos alunos pesquisadores um contato mais direto com a realidade dos alunos e da instituição escolar, podendo inclusive ter contato tanto com o nível privado, quanto público. Sendo assim, também se recomenda que este tipo de experiência continue ocorrendo com os futuros educadores, ou seja, nas licenciaturas, principalmente porque contempla não só o estudo da teoria, mas a modificação da realidade. 


\section{REFERÊNCIAS}

AKKARI, A. J. Desigualdades educativas estruturais no Brasil: entre estado, privatização e descentralização. Educação e Sociedade, Campinas, v. 22, n.74, p. 163-189, 2001.

BALZAN, N. C. Sete asserções inaceitáveis sobre inovação educacional. Educação \& Sociedade, São Paulo, n. 6, p. 19-30, jun. 1980.

BELLINI, M.; FRASSON, P. C. A metáfora guerra na comunicação das idéias de HIV/ Aids em livros didáticos. Revista Brasileira de Estudos Pedagógicos, Brasília, v. 87, n. 217, p. 327-338, set./dez. 2006.

BONETTO, D.; CRUZ, F. M. M.; CARNEIRO, R. M. Doenças sexualmente transmissíveis (DST), AIDS e Hepatite-B: antigas preocupações, novos desafios. Adolescência Latinoamericana, Porto Alegre, v. 1, n. 3, p. 137-138, out./dez. 1998.

BRASIL. Ministério da Educação e do Desporto. Parâmetro Curricular Nacional: terceiro e quarto ciclos do ensino fundamental. Introdução aos parâmetros curriculares nacionais. Brasília: Ministério da Educação, 1998.

BRASIL. Instituto Nacional de Estudos e Pesquisas Educacionais Anísio Teixeira (INEP-BR). Censo Escolar da Educação Básica 2012 - Resumo Técnico. Disponível em: <http:/download.inep.gov.br/educacao_basica/censo_escolar/resumos_tecnicos/ resumo_tecnico_censo_educacao_basica_2012.pdf>.Acesso em: 26 set. 2013.

BRASIL. Ministério da Saúde (BR). Dados e pesquisas em DST e Aids. Jan. 2011a. Disponível em: <http://www.aids.gov.br/pagina/dst-1> Acesso em: 24 ago. 2013.

BRASIL. Ministério da Educação. Educação. Jun. 2011b. Disponível em: < http://www. brasil.gov.br/educacao/2011/02/educacao>. Acesso em: 26 set. 2013.

BRASIL. Ministério da Saúde. Ministério aumenta faixa etária de vacina conta HPV. Portal da Saúde. SUS. 2013. Disponível em: < http://portalsaude.saude.gov.br/portalsaude/noticia/13360/162/ministerio-da-saude-amplia-faixa-etaria-da-vacina-contra-hpv. html>. Acesso em: 29 set. 2013.

BRETAS, J. R. S.; OHARA, C. V. S.; JARDIM, D. P.; MUROYA, R. L. Conhecimento sobre DST/AIDS por estudantes adolescentes. Revista da Escola da Enfermagem USP, São Paulo, v. 43, n. 3, p. 551-557, 2009.

BRÊTAS, J. R. S.; OHARA, C. V. S.; JARDIM, D. P.; MUROYA, R. L. Conhecimentos de adolescentes sobre Doenças Sexualmente Transmissíveis: subsídios para prevenção. Acta paulista de enfermagem, São Paulo, v. 22, n. 6, 2009.

CAMARGO, B. V.; BERTOLDO, R. B. Comparação da vulnerabilidade de estudantes da escola pública e particular em relação ao HIV. Estudos de Psicologia, Campinas, v. 23, n. 4, out./dez. 2006.

CASTRO, M. G.; ABRAMOVAY, M.; SILVA, L. B. Juventudes e sexualidade. Brasília: UNESCO Brasil, 2004. 
CHARLOT, B. Relação com o saber e com a escola entre estudantes de periferia. $\mathrm{Ca}$ dernos de Pesquisa, São Paulo, n. 97, p. 47-63, 1996.

COSTA, R. H. S.; DINIZ, E. J. M.; FERREIRA, C. C. F.; RIBEIRO, M. W. C.; SILVA, R. B.; SILVA, D. G. K. C. Percepção de discentes sobre DST/HPV em uma Escola Pública no Município de Santa Cruz/RN. Revista de Biologia e Farmácia, Rio Grande do Norte, v. 4, n. 2, 2010.

DEMO, P. Escola pública e escola particular: semelhanças de dois embrólios educacionais. Ensaio: Ava. Pol. Públ. Educ., Rio de Janeiro, v. 15, n. 55, p. 181-206, abr.jun. 2007.

FAVARETTO, J. A.; MERCADANTE, C. Biologia. Volume único. São Paulo: Moderna, 2003.

FERREIRA, D. A.; GAMA, E.; SILVA, H. H. O.; PADILHA, V. H.; BARRETO, A. A.; RODRIGUES, E. G.; MACHADO, M. A.; SILVA, A. F.; GOMES, F. J.; FERNANDES, M. A.; ROCHA, A. C.; MACHADO, H.; SANTOS, R. A.; RIBEIRO, A.; SANTOS, A. F.; GONÇALVES, A. O. A.; SILVA, G. Indisciplina e desinteresse do aluno da rede oficial de ensino: uma abordagem da sociologia da educação. Revista Augustus, n. 24, ago. 2007.

FERREIRA, M. P. Nível de conhecimento e percepção de risco da população brasileira sobre HIV/Aids, 1998 e 2005. Rev Saúde Pública, n. 42, Supl 1, p. 65-71, 2008.

FONSECA, A. Biologia. São Paulo: Cia. Editora Nacional, 1999.

GARCIA, I. Vulnerabilidade e Resiliência. Carta ao Editor. Adolesc. Latinoam., v. 2, n. 3, p. 128-130, abr. 2001.

JARDIM, D. P.; BRÊTAS, J. R. S. Orientação sexual na escola: a concepção dos professores de Jandira - SP. Revista Brasileira de Enfermagem, São Paulo, v. 59, n. 2, p. 157-62, 2006.

LOPES, S. Biologia Essencial. São Paulo: Saraiva, 2003.

MAIA, A. C. B.; ARANHA, M. S. F. Relatos de professores sobre manifestações sexuais de alunos com deficiência no contexto escolar. Interação em Psicologia, Bauru/Marília, v. 9, n. 1, p. 103-116, 2005.

MARQUES, E. S.; MENDES, D. A.; TORNIS, N. H. M.; LOPES, C. L. R.; BARBOSA, M. A. O conhecimento dos escolares adolescentes sobre Doenças Sexualmente Transmissíveis/AIDS. Revista Eletrônica de Enfermagem, v. 8, n. 1, p. 58-62, 2006. Disponível em: $<$ http://www.fen.ufg.br/revista/revista8_1/original_07.htm>. Acesso em: 26 set. 2013.

MARTINS, L. B. M.; COSTA-PAIVA, L.; D OSIS, M. J.; SOUZA, M. E. de; PINTO NETO, A. M.; TADINI, V. Conhecimentos sobre métodos anticoncepcionais por adolescentes. Rev. Saúde Pública, v. 40, n. 1, p. 57-64, 2006.

ORGANIZAÇÃO DOS ESTADOS IBERO-AMERICANOS - OEI. Censo Escolar registra 51,5 milhões de estudantes matriculados em 2010. 2010. Disponível em: <http://www. oei.es/noticias/spip.php?article8057\&debut_5ultimasOEI=80>. Acesso em: 29 set. 2013. 
PARKER, R. G. Corpos, prazeres e paixões: a cultura sexual no Brasil contemporâneo. São Paulo: Editora Best Seller, 2000.

PINHEIRO, J.; ZEITOUNE, R. C. G. Hepatite B: Conhecimento e medidas de biossegurança e a saúde do trabalhador de enfermagem. Revista de Enfermagem, Rio de Janeiro, v. 12, n. 2, p. 64-258, jun. 2008.

RIBEIRO, P. R. C.; SOUZA, D. O. Falando com professoras das séries iniciais do ensino fundamental sobre sexualidade: a presença do discurso biológico. Revista Enseñanza de las Ciencias, Barcelona, v. 21, p. 67-75, 2003. Disponível em: <http://repositorio.furg. br:8080/jspui/handle/1/1625>. Acesso em: 8 set. 2011.

SAITO, M. I.; LEAL, M. M. Educação sexual na escola. Pediatria, São Paulo, v. 22, n. 1, p. $45-48,2000$.

SILVA, M. P., CARVALHO, W. L. P. O Desenvolvimento do Conhecimento Pedagógico do Conteúdo de Sexualidade na Vivência das Professoras. Ciência \& Educação, Campinas, v. 11, n. 1, p. 73-82, 2005.

SIMÕES, C. B. Vacinas contra o HPV: Uma visão crítica. Diagn Tratamento, Guarulhos, v. 15, n. 2, p. 92-5, 2010.

SOARES, J. L. Biologia. Volume único. São Paulo: Scipione, 1999.

SOUZA, M. M.; DEL-RIOS, N. H. A.; MUNARI, D. B.; WEIRICH, C. F. Orientação sexual: conhecimentos e necessidades de professores de um Colégio Público de Goiânia-GO. Revista Eletrônica de Enfermagem, Goiânia, v. 10, n. 2, p. 460-471, 2008. Disponível em: <http://www.fen.ufg.br/revista/v10/n2/v10n2a17.htm>. Acesso em: 5 set. 2013.

THIOLlENT, M. Pesquisa-ação nas organizações. 2. ed. São Paulo: Atlas, 2009.

TINSLEY, B.; LEES, N. B.; SUMARTOJO, E. Child and adolescent HIV Risk: Familial and cultural perspectives. Journal of Family Psychology, 2004. (in press).

VEIGA, I. P. A. Técnica de ensino: Por que não? Campinas: Papirus, 1996.

VYGOTSKY, L. S. Obras Escogidas. Madrid: Visor, 1995. v. III.

WERNECK, V. R. Sobre o processo de construção do conhecimento: o papel do ensino e da pesquisa. Ensaio: Aval. Pol. Públ. Educ., Rio de Janeiro, v. 14, n. 51, p. 173-196, abr./jun. 2006.

Texto recebido em 04 de maio de 2015. Texto aprovado em 25 de agosto de 2015. 